\title{
Familial Trend and Socioeconomic Status of the Hypertensive Patients Attending at Hypertension Clinic
}

\author{
KAZI JAHANGIR HOSSAIN, ${ }^{1}$ NAZMA PARVIN,${ }^{2}$ A WAZED, ${ }^{3}$ MD. SHAMSUL ALAM, ${ }^{4}$ MD. MUSTAFA KAMAL ${ }^{5}$
}

\begin{abstract}
:
The aim of the study was to investigate familial trend and socioeconomic status of the hypertensive patients attending at the Hypertension Clinic of Dhaka Medical College Hospital, Dhaka. The study period was from July 2009 to June 2010. A total of 417 patients were recruited of which 245 were male and 172 female respectively, and selected consecutively on the basis of defined criteria. The research instrument was an interviewer-administered questionnaire. For assessment of familial trend of hypertension, first and second degree relatives of the respondents were investigated. Results showed that majority of the respondents were educated of which $22.1 \%(n=92), 18.2 \%(n=76), 19.9 \%(83)$ and $13.7 \%(n=57)$ were secondary, higher secondary, graduate and postgraduate educated respectively. In profession, $64.4 \%(n=I I I)$ female had household works, and $56.8 \%(n=139)$ male were in service and $41.2 \%(n=101)$ businessmen and had monthly income of $T k$. 10,000 to 80,000 . The mean age of them was $47.4 \pm 6.9$ years and $\mathrm{BMI}$ was $25.5 \pm 3.0 \mathrm{~kg} / \mathrm{m}^{2}$. The nutritional status of them were normal in $40.5 \%(n=169)$ and rest had different degree of malnutrition. In malnutrition, $53.1 \%(n=130)$ male were overweight, $2.9 \%(n=7)$ obese and $0.8 \%(n=2)$ undernourished; and $5 I .2 \%(n=88)$ female were overweight, $I I .0(n=19)$ obese and $I .2 \%(n=2)$ undernourished respectively. About $70.5 \%(n=294)$ of the studied hypertensive patients had positive history of hypertension in first and second degree relatives of which $17.3 \%(n=72)$ had single member positive history of hypertension, $18.2 \%(n=76)$ two, $16.8 \%(n=70)$ three, $14.1 \%(n=69)$ four and $4.1 \%(n=17)$ five members. In single member positive, most of them were in first degree relatives; in two members, $67.1 \%(n=51)$ were in first degree relatives and $27.6 \%(n=21)$ in both first and $2^{\text {nd }}$ degree relatives; in three members, $64.3 \%(n=45)$ were in $1^{\text {st }}$ degree and $31.4 \%(n=22)$ in both $I^{\text {st }}$ and $2^{\text {nd }}$ degree; in four members, $31.9 \%(n=22)$ were in $1^{\text {st }}$ degree relationship, $17.4 \%(n=12)$ in $2^{\text {nd }}$ degree and $50.7 \%(n=35)$ in both $1^{\text {st }}$ and $2^{\text {nd }}$ degree; and in five members, $17.6 \%(n=3)$ and $82.4 \%(n=14)$ in second degree, and both $I^{\text {st }}$ and $2^{\text {nd }}$ degree relatives respectively. Heath education and behavioral change intervention programs among the hypertensive population may be one of the most important applicable ways to control and/or prevention of hypertension and its complications in Bangladesh.
\end{abstract}

Keyword: Familal trend, Hypertension, Socioeconomic status

\section{Introduction:}

Hypertension is the most common and leading cause of morbidity and mortality in the industrial world as well as becoming an increasingly widespread disease in the developing countries. It is one of the 10 leading reported causes of death and about $4.0 \%$ deaths are due to hypertension and/or complications of hypertension in Bangladesh ${ }^{1}$. The top-most risk factors for the development of future hypertension are increased intake of sodium salt, use of tobacco products such as cigarette, bidi, sadapata, jarda and gul, obesity, elevated level of serum cholesterol, lack of physical exercise, excess stress and anxieties, and positive genetic predisposition ${ }^{2-7}$. In fact, an individual cannot change his/her genetic predisposition, age or gender, but he/she can change or modify or avoid other risk factors. The risk factors, which can be adjusted or modified through lifestyle advice, are sodium salt intake, tobacco products use, obesity, serum cholesterol level, physical exercise, stress and anxieties, dietary intake and improper lifestyle functions ${ }^{8}$. Prevalence of hypertension is $15-20 \%$ among adult population in Bangladesh ${ }^{9}$. The cardiovascular diseases such as ischemic heart diseases, stroke, and heart failure are one of the major chronic diseases and are the leading cause of death and disability in Bangladesh. High blood pressure is one of the most important direct causes, accounting 60 percent of all strokes and 50 percent of all

1. Assistant Professor, Department of Health Education, NIPSOM, Mohakhali, Dhaka

2. Senior Stuff Nursem, Dhaka Medical College Hospital, Dhaka

3. Assisant Professor and Head, Department of Occupational and Environmental Health, NIPSOM, Mohakhali, Dhaka

4. Medical Officer, Department of Health Education, NIPSOM, Mohakhali, Dhaka

5. Assistant Professor, Department of Nutrition and Biochemistry, NIPSOM, Dhaka

Correspondence : Dr. Kazi Jahangir Hossain,Assistant Professor, Department of Health Education, National Institute of Preventive and Social Medicine (NIPSOM), Mohakhali, Dhaka, Email: hossain.jahangir59@yahoo.com 
heart diseases. Nearly 15 million adults have been suffering from hypertension, among them, $49.0 \%$ in urban and $17.0 \%$ in rural elderly hypertension population are found aware of their high blood pressure of which, only $4.5 \%$ in urban and $3.1 \%$ in rural have found controlled blood pressure ${ }^{10}$. However, awareness about hypertension among the hypertensive population is one of the important applicable ways to minimize this human catastrophe.

The ultimate aim of this study is to investigate familial trend and socioeconomic status of the hypertensive patients to decrease morbidity and mortality due to hypertension. It is a grave threat to the public health in Bangladesh. Because of, most of the risk factors are highly prevalent in Bangladesh. In addition, people living with hypertensions are the topmost high-risk subpopulations who become physically disabled all on a sudden. Therefore, the aim of this work and in continuation of research in this field was to investigate familial trend and socioeconomic status of the hypertensive patients attending at hypertension clinic in Dhaka Medical College, Dhaka. The outcome will, significantly, be supportive and enhance the national preventive activities against hypertension

\section{Materials and Methods:}

\section{Study population}

The studied populations were the patients had been suffering from hypertension. Most of them attended voluntarily at the Hypertension Clinic of the Dhaka Medical College Hospital Dhaka and few were refereed patients from other departments from July 2009 to June 2010. A total of 417 patients were included in this study, among them, 245 were male and 172 female respondents. They were selected consecutively on the basis of defined criteria that were included in clinical manifestation of hypertension, irrespective of age and gender, and did not suffer from co-morbid mental disorders and used illicit drugs. Research instrument was an interviewer-administered questionnaire. The questionnaire was developed and pre-tested among the admitted patients, who were excluded from the study population. The questionnaire was designed to include general information, socioeconomic, anthropometrical data and family profile of the respondents. The socioeconomic profile included education, occupation, monthly income, age and marital status of the respondents. The anthropometrical device included height, weight and body mass index (BMI). The BMI was used to assess nutritional status of the respondents. For assessment of the familial trend of hypertension, first and second degree relationship such as father, mother, brother and sister; and chacha, fupu, mama and khala of the respondents were investigated.
Initially, an appointed research assistant briefed objectives, benefits, risks and burdens of this study to the patients and their close relatives. Only positive respondents were selected as research participant consistent with the selection criteria. A written informed consent was taken from each of the selected patients maintaining full autonomy. The research assistant also recorded socioeconomic-family profile of them following the questionnaire. A Medical Officer, under the direct supervision of the Resident Physician, was assigned for the diagnosis of hypertension and to take interview about familial trend of hypertension following the questionnaire. Each of the participants was examined individually in a separate room for maintaining their privacy and confidentiality strictly as well. In addition, close relatives were also interviewed, if necessary. Finally, the research assistant measured height and weight of the hypertensive patients using standard measuring scale. The study did not involve in any social, mental or physical risk to the patients. Prior to conduct, institutional permission was taken from the concerned authority of the hospital. The procedures followed for this study were in accordance with the CIOMS guidelines as updated in $2002^{11}$. No wedge-compensation was given to the participants.

\section{Statistical analysis}

A software package of SPSS (version 12.0: SPSS Inc., Chicago, IL, USA) was used to analysis the data. Descriptive statistics was used for all variables. Values were expressed as percentage.

\section{Results:}

Socioeconomic profile of the studied hypertensive patients is summarized in the Table-I. Majority of the respondents were found educated, among them, $22.1 \%(n=92)$, $18.2 \%(n=76), 19.9 \%(83)$ and $13.7 \%(n=57)$ were secondary, higher secondary, graduate and postgraduate educated respectively. In graduate and postgraduate, male were found comparatively higher status than that of female. In profession, $64.4 \%(n=111)$ female had household works only and $32.0 \%(n=55)$ had service. Among male, about 57.0\% $(n=139)$ were service holders and $41.2 \%(n=101)$ businessmen. Almost all male respondents had monthly income ranged 10,000 to 80,000 Taka. On the other hand about $65.0 \%(n=112)$ female had no income.

The table-II represents the age, marital status, BMI, and nutritional status of the participant hypertensive patients. Results showed that $79.0 \%(n=328)$ of them in both sexes had age above 40 years. Among them, $47.8 \%(n=117)$ of male had age 41-50 years and 31.8\% $(n=78)$ were $51-60$ years; $45.4 \%(n=78)$ of female had age $41-50$ years and $31.9 \%(n=55)$ 
were 51-60 years respectively. Only 21.3(n=89) of both sexes had age below 40 years. The mean age of them were $47.4 \pm 6.9$ years and all were found married. Results also showed that $58.5 \%(\mathrm{n}=244)$ of the studied hypertensive patients in both sexes had BMI above $25.0 \mathrm{~kg} / \mathrm{m}^{2}$ and $40.5 \%(\mathrm{n}=169)$ were 18.5-25.0, and rest had below 18.5. Among them, $53.1 \%(n=130)$ of male had BMI $25.1-30.0$ and $2.9 \%(n=7)$ were $30.1-37.2 ; 51.2 \%(n=88)$ of female had BMI 25.1-30.0 and $11.0 \%(n=19)$ were $30.1-37.2$ respectively. Nearly $43.2 \%(106)$ male and $36.6 \%(n=63)$ female had BMI18.5-25.0 respectively. The average BMI of the studied patients was 25.6 \pm 3.0 . Nutritional status of the studied hypertensive patients were found normal in $40.5 \%(n=169)$ and rest had different degree of malnutrition. Among them, 53.1\%(n=130) male were overweight, $2.9 \%(\mathrm{n}=7)$ obese and $0.8 \%(\mathrm{n}=2)$ undernourished; and $51.2 \%(\mathrm{n}=88)$ female were overweight, $11.0(n=19)$ obese and $1.2 \%(n=2)$ undernourished respectively.

The familial trend of hypertension was summarized in the Table-III. Results showed that $70.5 \%(n=294)$ of the studied hypertensive patients had positive history of hypertension in first and second degree relationship. Among them, $17.3 \%(n=72)$ had single member positive history of hypertension, $18.2 \%(\mathrm{n}=76)$ two members positive, $16.8 \%(n=70)$ three members positive, $14.1 \%(n=69)$ four members positive and $4.1 \%(n=17)$ five members positive history of hypertension. Only $29.5 \%(n=123)$ had no family history of hypertension. In single member positive, most of members were in first degree relationship (Table 3). In two members positive, $67.1 \%(\mathrm{n}=51)$ were found in first degree relationship, $5.3 \%(n=4)$ in second degree and $27.6 \%(n=21)$ in both first and $2^{\text {nd }}$ degree relationship respectively. Among the history of three members positive, $64.3 \%(n=45)$ were in $1^{\text {st }}$ degree relationship, $4.3 \%(n=3)$ in $2^{\text {nd }}$ degree, and $31.4 \%(n=22)$ in both $1^{\text {st }}$ and $2^{\text {nd }}$ degree relationship. In the history of four members positive, $31.9 \%(\mathrm{n}=22)$ were $1^{\text {st }}$ degree relationship, $17.4 \%(\mathrm{n}=12)$ in $2^{\text {nd }}$ degree and $50.7 \%(\mathrm{n}=35)$ were in both $1^{\text {st }}$ and $2^{\text {nd }}$ degree relationship. Finally, in five members positive history of hypertension, $17.6 \%(n=3)$ and $82.4 \%(n=14)$ in second degree, and both $1^{\text {st }}$ and $2^{\text {nd }}$ degree relationship respectively. There was no $1^{\text {st }}$ degree positive among the five members positive history of hypertension.

Table-I

Socioeconomic status of the participant hypertension patients $(n=417)$

\begin{tabular}{|c|c|c|c|c|c|c|}
\hline \multirow[t]{2}{*}{ Parameters } & \multicolumn{2}{|c|}{ Male $(n=245)$} & \multicolumn{2}{|c|}{ Female $(n=172)$} & \multicolumn{2}{|c|}{$\operatorname{Total}(\mathrm{n}=417)$} \\
\hline & Number & $\%$ & Number & $\%$ & $\%(\mathrm{n})$ & Average \\
\hline \multicolumn{7}{|l|}{ Education } \\
\hline Illiterate & 7 & 2.9 & 8 & 4.7 & $3.6(15)$ & \\
\hline $1-8$ Class & 40 & 16.3 & 54 & 31.4 & $22.5(94)$ & \\
\hline $9-10$ Class & 44 & 18.0 & 48 & 27.9 & $22.1(92)$ & \\
\hline $11-12$ Class & 50 & 20.4 & 26 & 15.1 & 18.2(76) & \\
\hline $13-14$ Class & 66 & 26.9 & 17 & 9.9 & $19.9(83)$ & \\
\hline 15-17 Class & 38 & 15.5 & 19 & 11.0 & 13.7(57) & \\
\hline \multicolumn{7}{|l|}{ Occupation } \\
\hline Household works & 5 & 2.0 & 111 & 64.5 & $27.8(115)$ & \\
\hline Business & 101 & 41.2 & 6 & 3.5 & $25.7(107)$ & \\
\hline Services & 139 & 56.8 & 55 & 32.0 & $46.5(194)$ & \\
\hline \multicolumn{7}{|l|}{ Monthly income (Taka) } \\
\hline Up to 10,000 & 32 & 13.1 & 14 & 8.1 & $11.0(46)$ & \\
\hline $10,000-20,000$ & 103 & 42.0 & 31 & 18.0 & $32.1(134)$ & 16,592 \\
\hline $20,000-30,000$ & 49 & 20.1 & 11 & 6.4 & $14.4(60)$ & \\
\hline $30,000-40,000$ & 27 & 11.0 & 3 & 1.7 & $7.2(30)$ & \\
\hline $40,000-80,000$ & 29 & 11.8 & 1 & 0.6 & $7.2(30)$ & \\
\hline Nil & 5 & 1.2 & 112 & 65.1 & $28.1(117)$ & \\
\hline
\end{tabular}


Table-II

Age, Marital status, BMI, and nutritional status of the respondents $(n=417)$

\begin{tabular}{|c|c|c|c|c|c|c|}
\hline \multirow[t]{2}{*}{ Parameters } & \multicolumn{2}{|c|}{ Male $(\mathrm{n}=245)$} & \multicolumn{2}{|c|}{ Female $(\mathrm{n}=172)$} & \multicolumn{2}{|c|}{$\operatorname{Total}(\mathrm{n}=417)$} \\
\hline & Number & $\%$ & Number & $\%$ & $\%(n)$ & $\mathrm{M} \pm \mathrm{SD}$ \\
\hline \multicolumn{7}{|l|}{ Age in year } \\
\hline $29-40$ & 50 & 20.4 & 39 & 22.7 & 21.3(89) & $47.4 \pm 6.9$ \\
\hline $41-50$ & 117 & 47.8 & 78 & 45.4 & $46.8(195)$ & \\
\hline $51-60$ & 78 & 31.8 & 55 & 31.9 & $31.9(133)$ & \\
\hline \multicolumn{7}{|l|}{ Marital status } \\
\hline Married & 245 & 100.0 & 172 & 100.0 & $100.0(417)$ & \\
\hline \multicolumn{7}{|l|}{ Body Mass Index } \\
\hline $17.0-18.5$ & 2 & 0.8 & 2 & 1.2 & $1.0(4)$ & \\
\hline $18.5-25.0$ & 106 & 43.2 & 63 & 36.6 & $40.5(169)$ & $25.6 \pm 3.0$ \\
\hline $25.1-30.0$ & 130 & 53.1 & 88 & 51.2 & $52.3(218)$ & \\
\hline $30.1-37.2$ & 7 & 2.9 & 19 & 11.0 & $6.2(26)$ & \\
\hline \multicolumn{7}{|l|}{ Nutritional status $^{12}$} \\
\hline Normal & 106 & 43.2 & 63 & 36.6 & $40.5(169)$ & \\
\hline Overweight & 130 & 53.1 & 88 & 51.2 & $52.3(218)$ & \\
\hline Obese & 7 & 2.9 & 19 & 11.0 & $6.2(26)$ & \\
\hline Undernourished & 2 & 0.8 & 2 & 1.2 & $1.0(4)$ & \\
\hline
\end{tabular}

Table-III

Familial trend of hypertension among the respondents $(n=417)$

\begin{tabular}{|c|c|c|}
\hline Parameter & Frequency & Percentage \\
\hline Single positive $(n=72)$ & 72 & 17.3 \\
\hline First degree relationship ${ }^{1}$ & 69 & 95.8 \\
\hline Second degree relationship ${ }^{2}$ & 3 & 4.2 \\
\hline Two positive $(n=76)$ & 76 & 18.2 \\
\hline First degree relationship & 51 & 67.1 \\
\hline Second degree relationship & 4 & 5.3 \\
\hline Mixed $^{3}$ & 21 & 27.6 \\
\hline Three positive $(\mathrm{n}=70)$ & 70 & 16.8 \\
\hline First degree relationship & 45 & 64.3 \\
\hline Second degree relationship & 3 & 4.3 \\
\hline Mixed & 22 & 31.4 \\
\hline Four positive $(n=69)$ & 69 & 14.1 \\
\hline First degree relationship & 22 & 31.9 \\
\hline Second degree relationship & 12 & 17.4 \\
\hline Mixed & 35 & 50.7 \\
\hline Five positive $(n=17)$ & 17 & 4.1 \\
\hline First degree relationship & Nil & 0 \\
\hline Second degree relationship & 3 & 17.6 \\
\hline Mixed & 14 & 82.4 \\
\hline $\begin{array}{l}\text { No family history of hyperten } \\
(\mathrm{n}=123)\end{array}$ & ion 123 & 29.5 \\
\hline
\end{tabular}

1. First degree relationship: Father, Mother, Brother and Sister.

2. Second degree relationship: Chacha, Fupu, Mama and Khala.

3. Mixed: Both first and second degree relationship.

\section{Discussion:}

Hypertension is the leading cause of morbidity and mortality among the adult human; no nation in the globe is immune to its fatal consequences. It is one of the major noncommunicable health problems in Bangladesh. In most cases, there is no specific causative agent for hypertension ${ }^{12}$. The top-most risk factors for the development of future hypertension are perhaps due to increased intake of sodium salt and sugar, increase use of tobacco products, overweight, dyslipidemia and hyperlipidemia, lack of physical exercise, excessive stress and anxiety, and positive genetic transmission ${ }^{2-5,13-14}$. Therefore, in order to address this national issue, the present study attempted to focus familial trend of hypertension and socioeconomic status of the hypertensive patients in Bangladesh.

Most of the respondent hypertensive patients were educated. Among them, males were found higher status in degree and above than that of female. In profession, majority of the female occupation was household works, and male had specific jobs such as business, service etc and had monthly income of Taka 10 thousands to 80 thousands but reverse scenario was found in female participants and they had no income. As a whole, Bangladesh is a densely populated country. About 160 million people live in this country. The trend in population growth, fertility, morbidity, mortality and migration from rural to urban areas are persistently creating hurdles in socioeconomic development. At present, nearly 
$48.0 \%$ people live below the poverty line. The socioeconomic characteristics of the studied hypertensive patients are consistent with the reported national statistical data ${ }^{15}$. The possible explanation is that the patriarchal society, religious stigmatism or fundamentalism as well as conventional sociocultural impact may be the important contributing factor for such type of socioeconomic characteristics of the women in Bangladesh. Socio-culture and religious backward tradition may be the unavoidable factors against women empowerment in the community. This trend of socioeconomic status is gradually changeing in Bangladesh. However, the socioeconomic status of the studied patients was found comparatively better than that of others. Education, family income and relatively better occupation are the leading factors for better socioeconomic status of them.

Eighty percent of the respondent patients had age above 40 years. Hypertension is an adult onset disease. Results are very much consistent with the other studies. Assessment of adult nutritional status is a complex procedure. No single method is available for assessment of the nutritional status of an adult individual. Multiple nutritional profiles such as anthropometrical, biochemical, clinical and dietary intake indices are need to analyze for the assessment of complete nutritional status ${ }^{16-17}$. Of the anthropometrical indices, body mass index (BMI), is usually and widely used to assess nutritional status of the adult population. It is relatively insensitive to $05 \%$ weight loss within 30 days or $10 \%$ weight loss over 6 months ${ }^{18}$. In this study, BMI was used to assess nutritional status of the hypertension patients. Results showed that about $60.0 \%$ in both sexes had different degree of malnutrition such as overweight and obese etc. The possible explanation, in general, occupation and income have a direct positive correlation with BMI. The socioeconomic status of the participant hypertension patients was found better than other population. Similar results were found in other studies ${ }^{19}$.

Around $70.0 \%$ respondents had positive family history of hypertension. They ensured 1-5 relatives suffered or had been suffering from hypertension. Of them, first-degree relationship (father, mother, brother and sister) was highly prevalent. Second degree relationship (Chacha, Fupu, Mama and Khala) and both of them were also significantly prevalent. The possible explanation is that the risk of hypertension is increased with age and some inherited genetic mutations, nervous sysytem overactivity, and insulin related metabolic syndrome, and low birth weight which are highly prevalent among the hyperternsive patients in Bangladesh. Similar result is also found in other studues ${ }^{5-7,20}$. Therefore, the familial trend of hypertension was found in the study strongly supported the genetic transmission of hypertension from parent to children.

In conclusion, socioeconomic status of the hypertensive patients was good and age of them was $47.4 \pm 6.9$ years. First degree and mixed relationship familial trend of hypertension was found significantly prevalent. Hypertension is a multifactorial disorder; no single factor is responsible for the development of hypertension. In fact, an individual can change or modify or avoid many risk factors to control hypertenaion or minimize the complication of hypertension. Heath education and behavioral change intervention programs among the hypertensive population may be one of the most important applicable ways to control and/or prevention of hypertension and its complications in Bangladesh.

\section{Acknowledgements:}

Authors thank the Ministry of Science and Information \& Communication Technology, Government of the People's Republic of Bangladesh for partial financial support. Authors also thank the Director and technical staff of the Hypertension Clinic, Dhaka Medical College Hospital, Dhaka for their kind assistance.

\section{Conflict of interest : None}

\section{References:}

1. Saha Ms, Sana NK, Shaha RK. Serum Lipid profile of hypertensive patients in the northern region of Bangladesh. Journal of Biological Science 2006; 14: 93-98.

2. Segura J, Ruilope LM. Obesity, essential hypertension and renin-angiotensin system. Public Health Nutr 2007; 10(10A): 1151-55.

3. Rodriguez-Iturbe B, Romero F, Johnson RJ. Pathophysiological mechanism of salt-dependent hypertension. Am J Kidney Dis 2007; 50(4): 655-72.

4. Lee JH, O'Keefe JH, Bell D, Hensrud DD, Holick MF. Vitamin D deficiency an important, common, and easily treatable cardiovascular risk factor?. J Am Coll Cardiol 2008; 52 (24): 1949-56.

5. Harrison M, Maresso K, Broeckel U. Genetic determinants of hypertension: an update. Curr Hypertens Rep 2008; 10(6): 488-95.

6. Esler M, Rumantir M, Kaye D. Sympathetic nerve biology in essential hypertension. Clin Exp Pharmacol Physiol 2001; 28(12): 986-89.

7. Reaven GM. Insulin resistance, the insulin resistance syndrome, and cardiovascular disease. Panminerva Med 2005; 47(4): 201-210.

8. Frier BM, Fisher M. Diabetes mellitus. In: Davidson's Principle \& Practice of Medicine, Boon NA, Colledge NR, 
Walker BR eds. $20^{\text {th }}$ edition, Churchill Livingstone, Elsevier 2006: 805-08.

9. Bangladesh Heart Foundation, Dhaka. Department of Research and Epidemiology http://www.nhfbd.org. epidemiology.php. Date: 2010:05:02.

10. Nazario B. Tips to lower high blood pressure. Holiday Miscellany 2007-05-18: 12-115. http://www.weekly holiday.net/2007/250507/mis.html. Date: 2010:04:13.

11. Council for International Organization of Medical Sciences (CIOMS). Biomedical research ethics: updating international guidelines. New York: CIOMS Publication 2002: 1-89.

12. Carretero OA, Oparil S. Essential hypertension, Part-1: definition and etiology. Journal of Circulation 2000; 101(3): 329-35.

13. Oparil S, Zaman MA, Calhoun DA. Pathogenesis of hypertension. Ann Intern Med 2003; 139(9): 761-76.

14. Hall, John E.; Guyton, Arthur C. Textbook of medical physiology. St. Louis, Mo: Elsevier Saunders, 2006: 228.
15. Bangladesh Bureau of Statistics. Statistical Yearbook of Bangladesh 2004. Finance, administration and M/S wing, Dhaka 2005: 49-94.

16. Baron RB. Nutrition. In: Current medical diagnosis and treatment, $38^{\text {th }}$ edition, Tierney Jr LM, McPhee SJ, Papadakis MA, eds A Lange Medical Book 1999: 1174-82.

17. Brooks $\mathrm{S}$ and Keams P. Enteral and parenteral nutrition. In: Present knowledge in nutrition, $7^{\text {th }}$ edition, Ziegler EE, Filere Jr LJ, eds, ILSI Press Washington DC, USA 1996: 530-39.

18. WHO. Physical status: the use and interpretation of anthropometry, WHO technical series 854; report of WHO expert committee, Geneva 1995: 362-64.

19. Hossain KJ. Immune profile and nutritional status of the drug addicts: role of vitamin $\mathrm{E}, \mathrm{C}$ and b-carotene on the immunity. PhD Thesis, INFS, University of Dhaka, 2002.

20. Bagby SP. Maternal nutrition, low nephron number, and hypertension in later life: pathways of nutritional program. J Nutr 2007; 137(4): 1066-72. 